disorder was carried out. Homes which resent interference by health officials welcome gladly nurses as a part of the school government. In many cities nurses have been supplied through private philanthropy. The objection to this is that these nurses are looked upon as almoners or missionaries of the society employing them. Neither have any right as such in our public schools.

While medical inspection in our schools has served a good purpose in awakening the public mind to the prevalence of contagious diseases as well as to physical defects among school children, it has per se accomplished very little in removing the causes of such misfortunes. Neither has it been of any service in deciding whether the order of studies now pursued in schools can be arranged so as to lessen fatigue to the child, nor has it pointed out the early signs of that fatigue now known to follow each other in a regular chronological order. The length of study period fitted to each grade; the question of one session or two sessions daily; the hours of sleep; the home worries, discouragements and labors; the social environment; all these questions concern problems which medical inspection has aided very little in solving. Candid medical inspectors say that the real inspection is done by the teacher, and that such cases only as she selects come to the inspector's notice. The Massachusetts Act says that " the state board of education . . . shall provide the pupils in the normal schools instruction and practice in the best methods of testing the sight and hearing of children." It would be of great value to both school and teacher if this normal school instruction included a fixed service, under a competent school nurse, among the children in their homes. It would give the studentteacher a view of child study and psychology such as no school course could offer, and its practical application in understanding and in developing each individual child would break up routinism and mass teaching. With such a corps of nurses and pupil-teachers, under school supervision, it would be a simple matter to construct a card system by which each child's height, weight, physical and mental development from his entrance into school life to its end would be visible at a glance. If the physician under whose supervision this branch of school work was placed could have a voice in the council and deliberations with the heads of the purely mental branches an educational body would be created such as does not exist to-day. Massachusetts, the American pioneer in educational methods, has taken the initiative in the act quoted above. Her educational interests are in the hands of energetic, conservative leaders. The future of the school in this country requires such statistics as I have proposed and an application of their teaching. The reciprocal relation of the school life and the home life cannot be established without them. Not until a uniform inquiry is carried out along these lines for a number of years can we hope to judge properly the question of physi- cal and mental development; and not until we reach such judgment can the right influence of education on future generations be estimated.

\section{OBSERVATION HOSPITALS OR WARDS FOR EARLY CASES OF MENTAL DISTURBANCE.}

BY L. VERNON BRIGGS, M.D., BOsTON.

In the Boston Medical and Surgical JourNAL of June 21, I published my first article on an observation hospital, giving some reasons why there should be one in Boston, as well as in other large cities in this country and also statistics of two hospitals which have been in existence for some time. I now want to state what further progress is being made in this new movement of observation wards and hospitals, and also add the testimony of some of our greatest men in psychiatry who believe that there is a crying need in this direction. I do not expect to appear in print again on this subject for some time, but I feel too much cannot be said in favor of this movement, and I trust that those who are deeply interested in this subject and are now studying it will soon come to some satisfactory and successful understanding so that relief may be had, not two or three years hence, but this year, and I believe that concerted action of physicians from the different societies (not alone any one society), or committees chosen by the societies, can bring some plan to a successful termination more quickly than in any other way. We have much to learn from Scotland and Germany and perhaps it would be well to have a commission go to these countries and study what is being done there. Last autumn some commissioners came here from Great Britain to see what we were doing for the feeble minded. This spring in Great Britain there was a royal commission, sitting in April, taking evidence toward the better control and care of the "feeble minded." Dr. Macpherson says, "By that term is implied those weaklings in every community who are not usually regarded as certifiable, but who, nevertheless, are notoriously unable to take proper care of themselves and who are a nuisance to society at large." Dr. Macpherson gave evidence before this commission and recommended, among other things, the extension of training institutions for feeble minded children, an examination of all habitual offenders by an expert in mental diseases and the establishment of special colonies for those who are found on such examination to be mentally defective. So far as Scotland is concerned he thinks that such measures would produce an immense reformation, in the large towns, especially.

In Scotland the observation ward under Dr. J. Carswell, connected with the Glasgow Hospital, has proved such a grateful relief to many in the incipient stages of insanity that the physicians have been trying to induce the government to establish observation wards in different parts of Scotland. Under date of April 2, 1906, Dr. John Macpherson writes me: "The. Imperial 
Parliament is so congested with its business that it has been quite impossible to get them to do anything. Consequently, the local government board and the lunacy board ${ }^{1}$ have taken the law into their own hands and without any statutory authority have drafted and imposed rules for the proper management of observation wards in poorhouses, such as they have in the Glasgow Hospital. They have instituted registers which must be kept and have limited the stay of all patients in the ward to a period of six weeks. The lunacy commissioners are to inspect regularly and to report to both boards." These boards are to be commended for their decisive action for the relief of that class of patients which would otherwise have to wait for commitment. They found no law forbidding such action as they have taken, and knowing that they were doing right and that they had the sense of the country behind them, they went ahead instead of waiting for the wheels of justice to turn, as they are turning here, very slowly.

Dr. Frederick Peterson, of New York, in a paper read before the Philadelphia County Medical Society at Philadelphia, Pa., Jan. 24, 1906, says that Philadelphia was the first city in the United States to preach the gospel of sickness for the insane, and the first to practise the doctrine. He says: " More than one hundred and fifty years ago Philadelphia established a hospital for the insane, which was a long step in advance of that period. Dr. Rush, of Philadelphia, was the Pinel of America. He abolished whipping as a remedial measure for insanity, and discarded the manacles and chains. Fifty years subsequent to the establishment of a hospital for mental disorders in Philadelphia, the first step was taken in the state of New York. In 1896, all the indigent insane in the state of New York had been placed under state care."

Now training schools for nurses are established in all New York State hospitals. A central pathologic institute or school of psychiatry is established at Ward's Island in the New York City asylums, to which the city physicians of the various hospitals of the state go for instruction in the latest scientific methods of study and treatment of the insane. This is under the direction of Dr. Adolph Meyer. A woman physician, a salaried dentist and an oculist are required at each hospital. Restraint by means of straps, etc., has been abandoned, and some wards have unbarred windows and doors; occupations for the patient have multiplied; special tuberculosis hospitals have been constructed, and in his paper Dr. Peterson urges that every great city should have emergency pavilions in connection with their hospitals to which patients supposed to be insane can be at once taken, not only for observation, custody and diagnosis, but for immediate treatment.

The Sheppard and Enoch Pratt Hospital for Mental and Nervous Diseases is what I should call an ideal psychopathic hospital. It seems to me to combine all that the foreign hospitals, or

1 Of which Dr. Macpherson is at the head. those now contemplated here, plan for so far as the patient is concerned. No chronic cases are taken, but only acute cases which are, persumably, curable. In the fourteenth annual report, the president states that, "It must constantly be borne in mind that Dr. Brush's definite purpose is to cure insanity, and in adhering to that attempt the resources must not be absorbed by chronic patients merely to be safely housed and comfortably cared for without hope of restoration." As is pointed out, "our doors are constantly open for cases of acute mental disturbances deemed by the staff probably curable." Dr. Edward N. Brush's report to the trustees for last year is as follows:

Remaining in the hospital Nov. 30, 1904,

Admitted during the twelve months,

105

110

Left during the year:

Recovered,

Improved,

Unimproved,

Died,

Not insane,

Under care Novemler, 1905,

$10 \mathrm{~s}$

107

Dr. Brush says in this report that during the first five years $16 \%$ of mental cases treated came voluntarily, while during the year just closed $33 \%$ of the admissions were voluntary, one third of these having previously been patients in the hospital. He says: "The influence of a voluntary application for admission upon the patient is most beneficial. He realizes that he is not at the hospital under coercion, but that he has exercised the same right of election in the matter of treatment that a person calling in a general practitioner for any state of ill health does." $\mathrm{He}$ can, upon three days' notice, sever his connection with the institution, unless he has grown decidedly worse and requires to be protected. Only two such cases has the hospital had during the year among the voluntary patients. Dr. Brush points out the need for instruction in psychiatry, and asks what would be thought of a course in surgery in which the instruction was given by lectures with no demonstrations whatever; or of a series of talks upon pneumonia without a chance to see or examine the patient. He says few medical schools in this country pretend to give any teaching at all upon the subject, and a majority of those who do give no clinical instruction whatever. In consequence, the condition of the patient is not infrequently made worse by the administration of a sedative or narcotic drug at inexperienced hands, and he adds, " Not infrequently, too, the early, and to the experienced observer, obvious, symptoms of mental disturbance are wholly mistaken or overlooked, and the patient who needs rest and freedom from distraction is sent on a journey, and the one who needs careful watching, because of the almost certain appearance of suicidal ideas, permitted to commit self-destruction."

F. Macfie Campbell, M.D., Ch.B., in an article. on " New York State and Psychiatric Teaching," 
June, 1905, says that in Great Britain, the question of the treatment of the insane is arousing considerable interest. It is being forced on the professional mind that it is not sufficient to clothe, house, feed, or even entertain the insane, but that medical responsibility goes still deeper. He says that while medical men have no difficulty in obtaining a special training in clinics organized to meet their needs, they find in Great Britain no psychiatric clinic where they may learn from a recognized teacher the special requirements of their work, especially if they are to be superintendents of insane hospitals. Whatever handicaps the physician means a loss to the patient; the insane patient is one whom we are bound to treat with special consideration, for he is no longer able to look after his own interests.

"This injustice to the insane is being felt by some of our medical schools, and in a short time, it is hoped the opportunities for study of mental diseases will be satisfactory. In Great Britain there are hopeful signs in the observation wards for the insane at the Eastern District Hospital, Glasgow. Edinburgh plans for a psychiatric clinic in the Royal Infirmary, and in the reception wards for the insane, which certain London hospitals propose to institute. In America, the University of Michigan has taken steps to open a psychiatric clinic. In New York State the initiative has been left by the university to the state, and the enlightened policy of the state in this respect ought to quicken our own feeling of responsibility."

About 1900, a movement for the establishment of a psychopathic ward in connection with the University of Michigan Hospital was started by Dr. William J. Herdman, professor of diseases of the mind and nervous system in the university. By an act of the legislature of 1901 an appropriation was granted for the erection of a building which was begun in 1903 and completed in 1905 . In its plan and equipment it is essentially an observation hospital. An annual appropriation of $\$ 5,000$ is authorized by the legislature to pay the salaries and the running expenses of the laboratory. It is a part of the university hospital. This fact gives opportunity for the study of mental diseases and it is also a teaching clinic. The ward was opened on Feb. 7, 1906, and is under the directorship of Dr. Albert M. Barrett, late of the Danvers Insane Hospital. The governing power of the institution is vested in a joint committee whose appointment rests with the university regents and the executive bodies of the various state asylums for the insane. The director is invested with the title of pathologist to the several asylums and professor of neuropathology in the medical department of the university. The hospital is especially designed and equipped for the study of acute cases of mental disturbance and has accommodations for forty patients, twenty of each sex. Arrangements are being made for hydrotherapeutic and electro-therapeutic treatments. The resident physician, Dr. George Milton Kline, is constantly in attendance. Patients may be admitted to the psychopathic ward in accordance with any of the iollowing processes:

(1) In cases where application shall be made under the statute to send persons claimed to be insane to either of the asylums in the state of Michigan, the judge of probate, before whom said application is pending, may require the assistance of three competent and skilled physicians who shall investigate the condition of said person and report the same to the judge of probate in writing and if said judge of probate upon investigation ascertains that there are present in the condition of the patient such features as render detention in a psychopathic hospital for a brief period advisable as a precautionary or curative measure, or if from such investigation said judge of probate shall be of the opinion that the case requires the services of specialists in the treatment of diseases other than those of the nervous system, he shall pass an order directing that such patient shall be transported for treatment to the psychopathic ward of the hospital of the University of Michigan. If the patient shall continue insane after any such special treatment he may be removed to and confined in such asylum of the State of Michigan as the probate judge may decree in his order of committal to the psychopathic ward.

(2) In case the superintendent of either of the asylums for the insane shall be or the opinion that the condition of mind of any person confined in such asylum is such that it might be advisable that the patient be sent to the psychopathic ward he shall cause such person to be conveyed to the psychopathic ward. If such patient shall be restored to sanity while in the said ward he shall be discharged, but in case such patient shall be found incurable, the superintendent of the university hospital shall cause said person to be returned to the asylum from which said person was received, the charges for the care, maintenance and transportation to be paid by the respective counties or by the state, as the patient may be a county or a state charge.

(3) Persons may commit themselves as voluntary patients under the same provisions as apply to such commitments to the state asylums. Dr. Edward Cowles, in the American Journal of Insanity, for October, 1905, says: "Psychiatry belongs to general medicine, and mental disease, like bodily disease, is not an entity nor an agency but the result of normal function acting under abnormal conditions."

At the International Medical Congress, held at Lisbon this year, 1906, Dr. Daniel R. Brower read a paper on "The Treatment of Acute Insanity in a General Hospital," in which he said that he began thirty years ago the treatment of selected cases of acute insanity in general hospitals and that he has never been without such cases since. The results have been such that he urges this plan on the profession generally. As regards treatment he says, "Intestinal fermentation is frequently present and there are few patients who do not need colonic flushings with normal saline solution and the internal use of intestinal antiseptics." 
On July 14, 1905, a deputation of medical men of the Province of Ontario, who believed that a certain class of cases often immediately adjudged insane, and confined in so-called insane asylums would be far better cared for in mental wards in general hospitals, waited on the Premier, the Honorable Mr. Whitney. The deputation comprised members of both the Toronto Clinical Society and the Ontario Medical Association, and because it was a large one, the proof is apparent that the profession of this province would like Dr. Mosher's Hospital at Albany, N. Y., duplicated. Dr. D. Campbell Meyers was the chief spokesman. The Premier promised them that the subject would have the immediate and careful consideration of his government. On April 3, 1906 , J. N. E. Brown, the superintendent of the Toronto General Hospital, writes me that " the Provincial Government has placed at the disposal of the trustees of this hospital, the sum of $\$ 5,000$ for the fitting up of a portion of the hospital for the treatment of functional nervous diseases, neurasthenia and the like. The wards have just been completed, and are now being furnished but will not be ready for a week or ten days yet." On June 29, 1906, he writes me as follows: "Our nervous wards have been open for several weeks. We have twelve beds, all of which are filled, and could readily, I think, keep double that many beds occupied." These wards are in charge of Dr. Meyers.

On June 28, 1906, Dr. Goldwater, of the Mt. Sinai Hospital, New York City, wrote me: "It is only a question of time when the kind of institution which you are agitating must be represented among the hospitals of New York. I think the examining physicians of the general hospitals of this city will bear me out in the statement that psychopathic hospitals are among the most pressing hospital needs of the metropolitan district."

On July 17, 1905 the following letter was sent to the editor of the London Times:

To THE EDITOR of THE Times:

Sir: The Lunacy Bill which has been introduced into the House of Commons by the attorney general, and now awaits second reading is a measure similar to that which has already twice passed the House of Lords. Its chief object is to provide milder treatment for early and recoverable insanity than is involved in the present compulsory certification. We venture to make an earnest appeal to the Prime Minister to afford the measure the small facilities which it needs, that the goverment and the House of Commons may not again be open to the charge of indifference to the urgent needs of this class of sufferers.

Yours,

W. S. Church,

W. R. Gowers,

George H. Savage,

David FerRier,

W. H. BroadBent.

Dr. John Macpherson in answer to inquiry about the above bill writes me as follows: "The London County Bill in the last House of Commons suffered the fate of many other bills during the expiring days of the late administration and was sacrificed in the general massacre of the innocents."
Maurice Craig, physician for mental diseases at Guy's Hospital, London, and senior assistant to the Bethlem Royal Hospital, London, states in his "Psychological Medicine" on the treatment of mental diseases, that mental disease, like many other maladies, must be treated in its early stages if complete recovery is to be obtained. He says: "Who would permit a case of phthisis to drift until the lungs had become riddled with cavities? But if from whatever cause such was the plight of the patient, the only treatment might well consist in attending to his board and lodging, and from time to time relieving urgent or distressing symptoms. One of the first points to be decided upon is where shall the patient be treated. In almost every case it is necessary to remove him from his home surroundings and place him in the charge of strangers. There are many courses which may be taken, the financial position of the patient being, as a rule, the determining factor. If the means are small, alternatives are correspondingly few, and in most instances the patient must be sent to some large private asylum, or to some hospital for mental diseases. As the law at present stands in England, anyone who takes into his house a person of unsound mind, who is certifiably insane, and yet who is not under certificates, renders himself liable to prosecution and a fine of $£ 50$."

Robert Jones, M.D., superintendent of Claybury near London, says in an article on the medical treatment of insanity, in the British Medical Journal of April 22, 1905, that " in the acute stage of no disease is care and attention more necessary, nor more expensive, nor is there more hope of cure, than in the early stages of insanity. It is essential to prevent exhaustion and to maintain the patient's strength by giving unirritating foods, easy of digestion, frequently and in small quantities; sleep is necessary, but sedatives and not hypnotics should be given."

Sir John Sibbald, M.D., in an article on the treatment of incipient mental disorders and its clinical teaching in the wards of general hospitals, published in the Journal of Mental Science, April, 1902 , says in the beginning of his paper that he hopes to make it clear both that the present opportunities for clinical instruction in insanity are singularly inadequate, and that the wards proposed would furnish the means of making such instruction efficient and complete. $\mathrm{He}$ says: " It is proper to put on record that the raising of the question at present is entirely due to my friend, Dr. John Macpherson, one of his Majesty's commissioners in lunacy, and, if, as I hope, the present discussion takes effect in the establishment of the wards we desire, it is to him that our gratitude will be due."

The first who effectually awakened an interest in the subject was Griesinger, who for some years previous to his appointment in 1865 , as professor of nervous and mental diseases in the University of Berlin, had insisted on the importance of providing efficiently for such teaching in every medical school, and who induced the authorities of the Royal Charité, the great general hospital 
at Berlin, to provide for clinical teaching hoth in neuropathy and psychopathy by giving him wards illustrative of each of these subjects.

The late Professor Laycock recognized so clearly this need that he suggested, in 1869 , that the managers of the Royal Infirmary should set apart wards to serve both for the treatment of mental disease and for the clinical instruction of medical students in insanity.

Sir Arthur Mitchell, in his Morison lectures in 1871 , also advocated the establishment of such wards, and so far succeeded in the advocacy that plans were prepared for such wards among the original plans for the buildings of the present Royal Infirmary.

Sir John Batty Tuke, though he afterwards supported a proposal that a special hospital for the treatment of mental disease should be established in London, said in an article in the Nineteenth. Century for April, 1889, that the ideal arrangement for teaching is a department for the treatment of insanity in connection with general hospitals. Continuing, he says that " as cases of mental disorder, as a rule, are excluded from the general hospitals, and the cases we have in view not having arrived at the stage which makes relegation to an asylum necessary or justifiable, it is, therefore, certain that a considerable number of patients are allowed to fall into incurable insanity who might have been, and indeed ought to have been, saved from that fate." He further says that the introduction of the proposed wards into the infirmary would also be an act of highest philanthropy, as tending to obliterate the line of demarkation which has been too long drawn tre between patients suffering from what are called the bodily diseases and patients suffering from what are called mental diseases.

In speaking of the out-patient department, Sir John Sibbald, M.D., refers to Dr. J. Batty Tuke, Jr., who conducts the Edinburgh New Town Dispensary, also the out-patient department for mental ailments in successful operation under Dr. Rayner at St. Thomas's Hospital in London, and a similar department established by Dr. Bevin Lewis, in connection with the West Riding Asylum at Wakefield. He advises a residence of not more than six weeks and that there should be no compulsory detention, which would exclude many patients.

He says in a discussion of the arrangement of the wards: "It is also necessary to keep in view the trend of medical opinion as to the treatment of mental disorders in their early stages, and there can be no doubt that this opinion has been steadily moving more and more towards the adoption of methods more closely resembling those resorted to in the treatment of bodily disease. Another recent development has brought wards for mental diseases more in line with ordinary hospital wards than they formerly were; this is the introduction of nursing by women into the male wards of asylums. In regard to this, I shall content myself with reference to the example of the wards for mental diseases in the general hospital at Copenhagen, where the nursing staff is almost entirely female, and to the position in the matter in the Sterling District Asylum. In that asylum the chief officer on the male side under the medical staff is a lady superintendent. Out of a total of 350 male patients nearly a third are, during the daytime, entirely under the care of female nurses, and this third includes the great majority of the male patients suffering from acute forms of mental disorder; 67 of these male patients are under the care of female nurses both night and day.

" It must be kept in mind that it is in the initial stage of mental disorder, before it has reached the stage when the relegation of a patient to an asylum would be resorted to, that it is most important that medical treatment should be careful and skillful, because it is then that it can be most effective; it is then that under careful guidance the patient may most hopefully be placed in circumstances that will allow the restorative forces of his constitution to regain control; that toxic processes may best be checked, and that the exhausted brain cells may be stayed in their progress towards disorganization.

"It is true of mental diseases, more perhaps than of any other class of diseases, that the earliest stages are those in which both teachers and students can best obtain much of the information necessary for the study of the nature and the causation of the malady.

"I think it is a matter of common experience that the patients whose curative treatment receives the most careful and capable attention are those whose good fortune it has been to be treated in wards where teaching is practised, and that it is the physicians and surgeons engaged in teaching who have chiefly contributed to our knowledge of the nature and the treatment of disease. I think it only reasonable, therefore, to expect that the observation of the earlier stages of mental disease in clinical wards would contribute notably to advance our knowledge. The point I wish chiefly to emphasize is, that under the .present arrangements, an important part of the instruction that the ordinary medical student should receive is omitted. He receives no direct clinical teaching as to the treatment of the incipient and the transitory phases of mental disease in their earliest stage, that is, before they have passed out of the hands of the general practitioner."

T. S. Clouston, M.D., in a discussion which he opened at the annual meeting of the Medical Psychological Association, Liverpool, July 25, 1902, on the "Possibility of Providing Suitable Means of Treatment for Incipient and Transient Mental Diseases in Our Great General Hospitals," said: "Does any adequate provision exist at present for the right treatment of the early stages of such diseases as have mental disorders for their chief symptoms, or for the slighter and more transient insanities, among the class who come to our general hospitals for advice and treatment? The answer must be ' no.' Our hospitals for the insane treat the developed cases in the best way known to modern science, but such cases as I 
have indicated cannot and should not be sent to them.

"In regard to mental disease, it is in its early and incipient stage that it is most curable; every case of mental disease has an early and incipient stage. During that stage it is not a case of technical legal insanity. It is a condition where you require to make the patients realize that there is something wrong with them. Dr. Mott has told us of the extreme importance from the purely scientific point of view of any form of bad brain habit. The rich can and do have means of treatment; the poor at present cannot. This does not apply to any other class of disease. Mental disease is the most pitiable of all. To allow such mental symptoms to run to such a degree of disturbance that they can be officially certified as technical insanity seems a cruel neglect as well as an expensive dereliction of duty on the part of society, for the man so afflicted ceases to be a producer and becomes incurable.

"Why should not an extension of the present asylum accommodation fulfill this purpose?

"The answer is that it cannot fully do so just because it is asylum accommodation, and, therefore, has attached to it the unfortunate and cruel prejudices and repulsions which would prevent patients from voluntarily taking advantage of it when they need it most and when it would do them most good. Many mental cases, too, are certifiable which should not be certified, and still more are not certifiable, and yet need definite treatment.

"What advantages would the present general hospitals have over asylums or any other mode of treatment?

" Firstly, anyone may go to seek advice at a hospital, or to be treated in one, without losing any of his self-respect, injuring his prospects in life, or going counter to any special prejudice in his mind. Secondly, the treatment of this class of disease - I attach enormous importance to this argument - would educate our poorer population, and, indeed, the whole population into entertaining the belief that mental disease is on all-fours with other classes of disease, and that it in no way implies shame or repulsion. If this education could take place to any degree, it would sweeten life to every family in which mental disease has occurred, and that would probably comprise every fourth or fifth family connection in the land. Besides, it would diminish one of the most poignant terrors in the lives of those who have suffered from the disease or fear its occurrence. The absence of this prejudice and fear would of itself greatly aid recovery.

"In the Copenhagen General Hospital, where, since 1863 , mental patients have been treated, the following result has occurred. Professor Pontoppidon, the professor of psychiatry there, says, 'The adding of the pavilion as an integral part of the hospital for general somatic diseases has influenced public opinion in modern and scientific directions, and has done away with much of the mysticism which, in public opinion, too orten clings to mental disorder. Patients and relations, , working which cannot be turned back. 